\title{
0 ensino da Geometria auxiliando a fabricação de embalagens
}

\author{
The teaching of geometry as an aid for \\ pack construction
}

\begin{abstract}
renction
Ana Cristina Schirlo

Sani de Carvalho Rutz da Silva

Resumo

O ser humano vem ao longo de sua existência desenvolvendo sua capacidade de transformar coisas utilizando-se da criatividade ao interagir com as mais diversas formas de composição. Nesse sentido, a indústria tecnológica vem se apropriando dos conceitos geométricos para criar e desenvolver novos produtos, inovando no ramo das embalagens e, assim, satisfazer as necessidades do mercado. Com o intuito de proporcionar a produção de conhecimento envolvendo conceitos geométricos, os alunos de $5^{a}$ série do Ensino Fundamental de uma escola pública, da cidade de Ponta Grossa, Paraná, realizaram atividades de cunho exploratório a partir da tendência através da resolução de problemas. As atividades foram pensadas e implementadas à luz do modelo de van Hiele. Espera-se que, a partir desse trabalho os alunos venham a apresentar mais facilidade para perceber as semelhanças e diferenças geométricas, uma vez que passam a integrar-se ao mundo das formas, a fazerem novas descobertas conceituais.
\end{abstract}

Palavras-chave: Geometria, resolução de problemas, modelo de van Hiele.

\begin{abstract}
The geometry comes from its origin occupying a place in the composition of forms in the world. For this reason, this study had as main objective to provide the production of knowledge of geometric concepts to students from 5th grade of elementary school to a school of public network in the city of Ponta Grossa, Paraná, through an activity of the exploratory mark light of the model of van Hiele. We sought to produce a package taking into account knowing that product is packaged and what is the profile of the consumer, will be held as the transport and what is the way of storing the product. For both, it took into account the knowledge of the concepts of geometry that students already have. This study aims to assist in the exploitation of the objects in the physical world, making them
\end{abstract}


more accessible to students, allowing connections between mathematics and other areas of knowledge.

Keywords: Geometry, troubleshooting, model of van Hiele.

\section{Introdução}

A Geometria é um dos ramos mais antigos da Matemática. Hogben (1970) e Eves (1997) sustentam essa afirmação ao dizerem que a história da Geometria teve seu início com o uso da linguagem pictórica ou hieroglífica. Sua expansão ocorreu pela necessidade da prática da mensuração de áreas agrícolas, por volta do ano 3000 a.C., no Oriente. Esse fato justifica a origem da palavra Geometria, que vem do grego e significa "medida da terra" ( geo $=$ terra e metria $=$ medida $)$.

Até então, o conhecimento geométrico, como qualquer outra forma de conhecimento, era empírico, rudimentar e brotava da observação do que o homem fazia em seu cotidiano. Os problemas geométricos eram resolvidos pela indução ou empiricamente, ou seja, de maneira prática, sem que houvesse uma preocupação com formalidades teóricas. Porém, com o aperfeiçoamento das técnicas agrícolas, passou-se a exigir do homem um conhecimento mais elaborado da Matemática e especialmente da Geometria. Segundo Eves (1997, p. 56):

O período de 3000 a.C. a 525 a.C. testemunhou o nascimento de uma nova civilização humana cuja centelha foi uma revolução agrícola. Novas sociedades baseadas na economia agrícola emergiram das névoas da Idade da Pedra nos vales dos rios Nilo, Amarelo, Indo, Tigre e Eufrates. Esses povos criaram escritas; trabalharam metais; construíram cidades; desenvolveram empiricamente a matemática básica da agrimensura.

Dessa forma, quando a cultura Egípcia mostrou, por meio dos vestígios históricos de sua civilização, que a sociedade soube erguer grandes construções sem a ajuda de máquinas, conclui-se que somente uma sociedade detentora de um conhecimento matemático, mais especificamente geométrico, conseguiria tais proezas, uma vez que a Geometria permite a percepção e a visualização do espaço, o reconhecimento e a abstração de formas, bem como a capacidade de representá-las por meio do desenho ou da construção do que foi idealizado.

Nesse entender, a Geometria ocupa, desde a sua origem, um lugar de destaque na composição das formas existentes, pois é um ramo da Matemática que apresenta situações do 
mundo real. Ela pode ser entendida como o conhecimento imediato da relação espaço/forma, visto que inicia com o sentido da visão e caminha em direção ao pensamento.

A Geometria é excepcionalmente rica em oportunidades para fazer explorações, representações, construções, discussões, de modo que o aluno pode investigar, descobrir, descrever e perceber propriedades. Nesse entender, atividades que envolvem Geometria podem proporcionar o desenvolvimento de um pensamento crítico e autônomo, já que pode favorecer a análise de fatos e relações, o estabelecimento de ligações entre eles e a dedução. É um componente importante, inclusive, no desenvolvimento da aritmética e da álgebra. Lopes (2005, p. 81) afirma que "o domínio dos conceitos geométricos básicos - como formas, medidas de comprimentos, áreas e volumes - é essencial para a integração de um indivíduo à vida moderna".

Segundo Lorenzato (1995, p. 5):

A Geometria está por toda parte..., mas é preciso conseguir enxergá-la... mesmo não querendo, lida-se no cotidiano com as idéias de paralelismo, perpendicularismo, semelhança, proporcionalidade, medição (comprimento, área, volume), simetria: seja pelo visual (formas), seja pelo uso no lazer, na profissão, na comunicação oral, cotidianamente se está envolvido com a Geometria.

Portanto, o ser humano vem ao longo de sua existência desenvolvendo sua capacidade de transformar coisas utilizando-se da criatividade ao interagir com as mais diversas formas de composição. Nesse sentido, a indústria tecnológica vem se apropriando dos conceitos geométricos para criar e desenvolver novos produtos, inovando no ramo das embalagens e, assim, satisfazer as necessidades do mercado.

Com o intuito de proporcionar a produção de conhecimento envolvendo conceitos geométricos,os alunos de 5a série do Ensino Fundamental de uma escola da rede pública, da cidade de Ponta Grossa, Paraná, realizaram algumas atividades de cunho exploratório através da resolução de problemas. Inicialmente, os alunos confeccionaram embalagens, depois as descreveram e por último elas foram exploradas em exercícios que envolviam conceitos geométricos. As atividades foram pensadas e implementadas à luz do modelo de van Hiele.

Espera-se que este trabalho venha somar-se a outros estudos já existentes sobre Geometria. Pois, a partir desse tipo de experiência, os alunos podem vir a apresentar mais facilidade para perceber as semelhanças e diferenças geométricas, uma vez que passam a integrar-se ao mundo das formas, a fazerem novas associações e descobertas conceituais. 


\section{A Geometria das Embalagens}

Estudos feitos por Lindquist e Shulte (1994), Lorenzato (1995), entre outros, apontam que, no Brasil, nas últimas décadas, a Geometria vem sendo tratada sem o reconhecimento de suas potencialidades, em todos os níveis de ensino e áreas de aplicação. Esses pesquisadores apontam que o ensino da Geometria, muitas vezes, é iniciado a partir da 5a série do Ensino Fundamental e é voltado, quase exclusivamente, ao ensino da Geometria Plana.

Além disso, a metodologia empregada para a ministração de aulas de Geometria geralmente restringe-se ao uso de modelos do ensino tradicional, distanciando, assim, a aprendizagem das necessárias relações que os alunos devem estabelecer com o mundo real.

Segundo Ostrower (1983), muitas propostas pedagógicas voltam-se apenas para o condicionamento operante e o aspecto mais importante da relação ensino-aprendizagem, que é formar o indivíduo por meio do conhecimento, acaba não acontecendo. Devido a esse fato, o ensino escolar atual deve diferenciar-se do ensino tradicional. Nesse entender, o ideal é que se busque envolver as questões sociais nos problemas escolares, pois o desenvolvimento de teorias científicas pode influenciar o desenvolvimento do pensamento das pessoas.

A adoção de uma abordagem metodológica não tradicional no ensino de Geometria é interessante, visto que a aprendizagem geométrica é necessária ao desenvolvimento do educando tanto em Matemática - pois inúmeras situações escolares requerem percepção espacial, o reconhecimento e a abstração de formas, a abstração de formas e a capacidade de representá-las por meio de desenhos - quanto em outras áreas do saber, como em Geografia, na leitura e interpretação de gráficos.

Essa abordagem permite que professor e aluno elaborem, desenvolvam e promovam discussões de relevância social no interior do contexto escolar. Procurando atender essas discussões, os PCNs (BRASIL, 1998, p. 51) afirmam que:

Os conceitos geométricos constituem parte importante do currículo de Matemática no ensino fundamental, porque, por meio deles, o aluno desenvolve um tipo especial de pensamento que lhe permite compreender, descrever e representar, de forma organizada, o mundo em que vive.

Nesse entender, os PCNs (BRASIL, 1998) propõem que o trabalho com Geometria deve ser feito a partir da exploração dos objetos do mundo físico, de obras de arte, pinturas, desenhos, esculturas, entre outros objetos. Ainda conforme afirmam os PCNs (BRASIL, 1998), a Geometria possibilita ao professor trabalhar com situações-problema reais, encontradas no dia-a-dia. É um tema pelo qual os alunos costumam se interessar espontaneamente. 
Vivemos em um mundo tridimensional. Logo, é necessário que tanto o professor quanto o aluno recorram ao raciocínio espacial para representar o mundo real. Sabe-se que a Geometria Espacial e os Sólidos Geométricos fazem parte do cotidiano. Portanto, em alguns setores industriais, esta Geometria é mais evidente. Com base neste fato, o setor de embalagens apropria-se muito bem desta ciência, transformando simples papéis e papelões em embalagens úteis para o dia-a-dia.

O mercado, por meio da concorrência dos produtos, tem exigido que o setor industrial produza, a cada dia, mais inovações na produção de embalagens. Essas inovações têm provocado no consumidor a chamada "febre do consumismo", pois muitas vezes ele acaba comprando um determinado produto simplesmente pela estética ou pela praticidade da embalagem. Dessa forma, a embalagem valoriza o produto sendo um atrativo comercial.

No entanto, ao confeccionar uma embalagem, a indústria tecnológica deve levar em consideração alguns pré-requisitos para poder decidir sobre o material mais apropriado à produção da embalagem: a) saber que produto será embalado; b) saber qual é o perfil do consumidor; c) como será realizado o transporte; d) qual será a forma de armazenagem do produto; e) qual será o prazo de validade do produto.

Esses pré-requisitos já haviam sido determinados por Rausing (1950), quando afirmou que "uma embalagem deve gerar mais economia do que ela custa". Isto significa que se devem produzir embalagens que protejam os alimentos e que não destruam os recursos naturais, além de não gastar muita energia na sua fabricação, estocagem e transporte.

Enfim, a indústria, além de levar em consideração os pré-requisitos mencionados, deve ter em vista os conhecimentos dos conceitos de Geometria - tanto Plana, quanto Espacial para obter êxito na confecção das embalagens. Como o principal objetivo de uma embalagem é proteger alimentos, aparelhos eletrônicos, entre outros objetos, pode-se dizer que a população atual tem necessidade da aplicação da Geometria e da Matemática para o desenvolvimento de novos produtos para atender o mercado mundial. Portanto, as inovações tecnológicas permitiram que se produzissem bens de consumo em enormes quantidades e fabricassem embalagens cada vez melhores, que garantissem o transporte seguro e a durabilidade desses bens.

\section{Procedimentos Metodológicos}

Com o intuito de proporcionar produção de conhecimento por meio da aplicação dos conceitos geométricos aos alunos de 5aㅗ série do Ensino Fundamental de 
uma escola da rede pública, na cidade de Ponta Grossa, Paraná, realizou-se atividades de cunho exploratório à luz do modelo de van Hiele.

O trabalho contemplou, em um primeiro momento, a construção de embalagens a partir dos conhecimentos empíricos dos alunos por meio da interpretação das formas do mundo concreto. Em um segundo momento, realizaram-se novas construções geométricas, agora com base nos conhecimentos adquiridos nas aulas de Matemática da 5a série, com cálculos e dimensões pré-estabelecidas. Essa experiência visava à demonstração do objeto geométrico construído. Para tanto, enfocou-se a tendência através da resolução de problemas pertencente ao Movimento da Educação Matemática ${ }^{1}$.

Para Onuchic (1999), problema é algo que, a princípio, não tem solução, solução essa que, no entanto, se procura encontrar. Corroborando essa definição, Van de Walle (2001) afirma que problema é qualquer tarefa ou atividade para a qual os estudantes não têm métodos ou regras prescritas ou memorizadas. Logo, a busca pela solução de problemas conduz a novas situações que se colocam com o objetivo de instigar a curiosidade matemática.

A abordagem sobre Resolução de Problemas vem passando por modificações desde as concepções de Polya (1949), que entendia que resolver um problema era encontrar um caminho quando nenhum outro caminho é conhecido.

Atualmente, Schroeder e Lester (1989) consideram a existência de três modos de abordar a Resolução de Problemas: ensinar a resolução de problemas, ensinar a resolver problemas e ensinar matemática através da resolução de problemas.

Esses novos modos de abordagem para a Resolução de Problemas sugerem novas formas de trabalho em sala de aula. Van de Walle (2001), Onuchic (2003) e Allevato (2005) têm experimentado o processo de ensinar matemática através da resolução de problemas, que possibilita usar um problema como ponto de partida e como norte para a aprendizagem de conceitos matemáticos.

Ensinar Matemática através da Resolução de Problemas é uma tendência de ensino que leva o aluno a apresentar soluções usando sua própria linguagem. Está de acordo com os PCNs (BRASIL, 1998), pois visa à ação por parte dos alunos. Machado $(1987$, p. 118) afirma que a tendência de ensino-aprendizagem de Matemática através da Resolução de Problemas consiste em:

${ }^{1}$ Movimento da Educação Matemática: teve início nos anos 70 por conseqüência do descambar da Matemática Moderna. Nesse movimento a Matemática passou a ser entendida como uma forma de linguagem, que é produzida e utilizada socialmente como representação do real e da multiplicidade de 
apresentar aos alunos, já no início do tratamento de um dado conteúdo, uma ou mais situações-problemas que possam levá-los a raciocinar sobre a necessidade de construir novos conceitos e processos, bem como a de associar outros periféricos, que venham a se conectar numa rede de significados.

A tendência de ensino-aprendizagem de Matemática através da Resolução de Problemas não deve ser confundida com a simples introdução de problemas de aplicação, comumente encontrados nos finais dos capítulos dos livros didáticos.

Corroborando com a tendência através da Resolução de Problemas, o modelo de van Hiele (1979), dará confiabilidade ao estudo. Muitos pesquisadores, interessados em encontrar soluções para os problemas com ensino de Geometria, tomaram como base de estudos a teoria de van Hiele. De modo geral, pesquisadores como Souza (2001), Nasser (2004), Sant' Anna (2004), Pereira (2005), Silva (2005) e Motta (2005) objetivavam testar a validade do modelo, sua viabilidade e as vantagens de sua aplicação.

O modelo de van Hiele sugere cinco níveis hierárquicos de atividades adequadas ao estudo da Geometria na identificação e construção dos entes geométricos. Apesar de ser um modelo hierárquico, ou seja, obedece à seqüência: das partes para o todo, ele é capaz de apontar lacunas de aprendizagem que o aluno apresenta. Assim, esse modelo permite que o professor possa organizar sua prática pedagógica para facilitar a aprendizagem do aluno. Pois, os alunos progridem de um nível para o seguinte, por meio de atividades adequadas e ordenadas. Cada nível é caracterizado por relações entre os objetos de estudo, por meio de uma linguagem própria. Esses níveis, segundo van Hiele (1959), são os seguintes:

Nível 1 - Visualização: neste nível, os alunos não reconhecem as partes das figuras, não percebem as relações entre os componentes das figuras nem entre as figuras. A comparação e a nomenclatura das figuras geométricas se dão por sua aparência global não por suas partes ou propriedades. Logo, o conhecimento de geometria é básico, a percepção das figuras geométricas ocorre de forma global e individual. A descrição das figuras é baseada principalmente em seus aspectos físicos e posição no espaço. As propriedades geométricas são utilizadas de forma imprecisa. Inicia-se a introdução de um vocabulário matemático para falar das figuras e descrevêlas.

Nível 2 - Análise: nesse nível, as figuras passam a ser identificadas por suas partes, mas ainda não é possível explicar as relações entre as diversas propriedades, entre as figuras e as definições não são compreendidas. O aluno ainda não consegue fazer uso dessas propriedades para resolver problemas, pois é nesse momento que o aluno inicia o reconhecimento das propriedades geométricas presentes em cada figura e passa a fazer generalizações das 
propriedades. Contudo, ainda não consegue fazer relação entre diferentes propriedades de uma figura nem entre figuras de outros grupos.

Nível 3 - Dedução informal: nesse nível, as relações entre as propriedades das figuras ou entre figuras já são compreendidas. Os alunos são capazes de deduzir as propriedades de uma figura e reconhecer classes de figuras. Por conseguinte, a partir desse nível os alunos compreendem a inclusão de classes e as definições geométricas e também seguem ou produzem um argumento informal. No entanto, a dedução ainda não é compreendida como um elemento de construção de uma axiomática. Por essa razão, é frequente a utilização de resultados empíricos e de técnicas de dedução, o que torna possível seguirem provas formais.

Nível 4 - Dedução formal: nesse nível, os alunos são capazes de construir uma demonstração, seguindo caminhos diversos, de compreender a diferença entre condição necessária e condição suficiente e de distinguir teorias contrárias. Os alunos passam a dominar o processo dedutivo e as demonstrações e reconhecem, assim, as condições necessárias e suficientes para fazer as deduções de modo a estabelecer a teoria geométrica no contexto de um sistema axiomático, passando a aceitar as diferentes possibilidades de se atingir um mesmo resultado.

Crowley (1987), em estudos posteriores aos de van Hiele (1959), apresenta formulações semelhantes para os níveis do modelo e acrescenta ao modelo de van Hiele mais um nível (o nível 5-Rigor).

Nível 5 - Rigor: nesse nível, os alunos são capazes de trabalhar com diferentes sistemas axiomáticos, euclideanos ou não, e compará-los. Os alunos apresentam capacidade de compreender demonstrações formais e de estabelecer teoremas em diversos sistemas, comparando-os, bem como deduções abstratas, baseando-se em um sistema de axiomas prédeterminado e estabelecer a compreensão da importância da precisão ao tratar de fundamentos e relações matemáticas.

De acordo com Morelatti e Souza (2006), o aluno, muitas vezes, encontra-se em um determinado nível de aprendizagem - segundo o modelo de van Hiele - e o professor, em suas aulas faz uso de um material didático, ou de um vocabulário não adequado ao nível em que o aluno se encontra o aluno. Dessa forma, o aluno não será capaz de acompanhar os processos de pensamento que o professor está empregando, logo, a aprendizagem e o progresso podem não ocorrer.

Nesse entender, para van Hiele, o aluno passa sucessivamente por níveis distintos, os quais são denominados reconhecimento, análise, abstração, dedução e rigor. Portanto, pode-se dizer que este modelo possui uma forte base estruturalista, estabelecendo estratégias 
metodológicas que favoreçam a resolução de problema e a interdisciplinaridade numa visão não linear.

\section{Proposta de Atividades e Discussão}

Todos os seres vivos se relacionam entre si e com o meio ambiente, mas apenas o homem atua conscientemente sobre ele. Esse mesmo homem tem sido responsável pelas grandes e rápidas transformações que estão ocorrendo em todo o planeta Terra. Essas mudanças passaram a se fazer presentes principalmente a partir do processo de urbanização ocorrido após a Segunda Guerra Mundial (1939-1945).

Um dos marcos dessa urbanização se deu quando a população rural passou a deixar o campo para tentar a vida na cidade. Esse movimento de êxodo rural passou a exigir um aumento no abastecimento de alimentos e bens de consumo nas cidades. A partir desse fato, propôs-se aos alunos da 5a série do Ensino Fundamental de uma escola pública da cidade de Ponta Grossa, uma situação-problema que objetiva à demonstração de um objeto geométrico. Essa situaçãoproblema contemplou, em um primeiro momento, a construção de embalagens a partir dos conhecimentos empíricos dos alunos por meio da interpretação das formas geométricas do mundo concreto. Em um segundo momento, elaboraram-se novas construções geométricas, agora com base nos conhecimentos adquiridos nas aulas de Matemática da 5a série, com cálculos e dimensões pré-estabelecidas.

\section{Primeiro Momento}

Inicialmente, no primeiro dia do desenvolvimento da atividade, o professor apresentou a seus alunos a seguinte situação-problema:

A Agência dos Trabalhadores do município de Ponta Grossa comunica que a Embalaperfex - fábrica de embalagens - está recolhendo pessoas para atuarem na área de criação de novos modelos de embalagens. Os interessados devem comparecer no dia 10 de junho às 10h00min horas da manhã no setor de recursos Humanos, munidos de uma embalagem modelo que atenda aos seguintes critérios: economia, qualidade, estética e praticidade. Os interessados deverão fazer uma demonstração do seu produto destacando as qualidades que tornam o seu modelo de embalagem a melhor opção.

Para resolver a situação-problema proposta, os alunos começaram a confeccionar uma embalagem. $E$, alguns alunos, inicialmente, argumentaram que não conseguiriam fazer. 
- Professor!Acho que não sei fazer embalagem nenhuma. Não vou poder me candidatar a esse emprego. (aluno A. T. S.)

- Nunca fiz nada parecido com uma embalagem. (aluno R. R. A.)

- Professor!Tem que recortar e colar? (P. R. A.)

- A minha folha já amassou de tanto eu dobrar e não fiz nada. (aluno E. T. M.)

Depois de muito dobrar e desdobrar, riscar e apagar, todos os alunos criaram o seu produto. Assim, com relação às formas, o pensamento geométrico dos estudantes desenvolveu-se inicialmente pela visualização e a grande maioria das embalagens que estes confeccionaram ficou com o formato de prisma retangular, nas mais diversas dimensões. De um modo geral, percebeu-se que os discentes apresentaram um nível inicial de visualização, pois reconheceram e reproduziram algumas figuras geométricas planas para confeccionar a embalagem.

Provavelmente, essa visualização se deu pela forma, e não pela identificação das propriedades geométricas. Ficou evidente que nenhum aluno planejou, ou seja, planificou a embalagem a ser confeccionada. Pois, para fazerem a planificação eles precisariam fazer uso de modelos geométricos e matemáticos como prismas, cubos e cilindros. E segundo, a fala dos próprios alunos, eles ainda não tinham conhecimento para realizarem com êxito a planificação da embalagem.

Isso pode ter acontecido pelo fato de esses alunos terem tido contato com a Geometria Plana separadamente da Geometria Espacial. Pois, ao propor apenas o estudo das figuras planas, o professor prejudica a criação dos modelos mentais que levam o aluno a desenvolver, inclusive, a sua capacidade de visualização espacial. Nesse entender, atividades de montar e de encaixe são importantes tanto para o desenvolvimento da intuição espacial e de habilidades para visualizar, interpretar e construir, quanto para a formação do pensamento geométrico dedutivo, uma vez que favorecem a visualização e a percepção do espaço ao redor do aluno.

No início da segunda aula desse momento da atividade, propôs-se, para todos os alunos, a apresentação das embalagens. Para tanto, o professor passou a ser considerado o representante do setor de Recursos Humanos da empresa Embalaperfex.

Nessa apresentação, houve a necessidade de os alunos mensurarem a embalagem que confeccionaram. Assim, eles deveriam expor:

- uma idéia de volume que a embalagem comporta; 
- especificar as diferentes possibilidades de armazenamento considerando a variedade das formas, explicando a utilidade de uso de sua embalagem, bem como as suas vantagens;

- o custo para fabricação da suposta embalagem, incluindo os gastos com matéria-prima e mão-de-obra;

- o público-alvo que se pretende atingir com a sua embalagem.

Durante as apresentações, alguns alunos se portaram tranqüilos; outros, ansiosos, e alguns, descompromissados. Mesmo assim, todos fizeram a exposição de suas embalagens, e destacaram-se os seguintes comentários:

- A minha embalagem tem o formato de um dado e tem capacidade para 6 (seis) bombons, pois assim você pode comprar esses bombons e presentear sua namorada. (aluno C. M. S.)

- Fiz uma caixinha sem tampa para comportar 200 (duzentos) gramas de bolachas. No lugar da tampa vai um protetor de plástico, assim o consumidor pode ver o produto que está comprando e não vai ficar caro o custo para a fabricação da embalagem. (aluno J. L. S.)

- Minha embalagem tem formato de um "saquinho" e é para armazenar doces. Não precisa de tampa é só enrolar um pedaço do "saquinho". Dá para levar doces no cinema e quase não custa nada. (aluno S. S.)

Porém, chamou a atenção a apresentação de uma aluna, não tanto pelo formato de sua embalagem, que era um prisma retangular, mas pela sugestão de utilidade e o público-alvo que pretendia atingir com o produto.

- Ofereço uma embalagem de $200 \mathrm{ml}$ para armazenar leite para ser levado para escola e ser consumido no recreio. Pois estamos em fase de crescimento e o leite é um alimento de extrema importância nessa fase. (aluno I. S. S.)

Essa idéia levou a uma atividade complementar, nesse primeiro momento. Com o uso das ferramentas notebook e internet, os alunos conectaram-se ao site de uma fábrica real, localizada na cidade de Ponta Grossa, para que pudessem ver como é a confeç̧ão de embalagens e de que material elas são confeccionadas. Após esse passeio online 
conhecendo a fábrica, os alunos enviaram um e-mail sugerindo a idéia da aluna que propôs a confecção de uma embalagem de $200 \mathrm{ml}$ para embalar leite.

Tudo isso se fez necessário para avaliar como os alunos produziram conhecimento sobre Geometria, levando em consideração aproveitamento do papel, criatividade, estética, praticidade e utilidade do produto. O resultado dessa atividade, além de desenvolver o elo entre a álgebra e a geometria, possibilitou alguns questionamentos por parte dos alunos a respeito de economia de material, estética, utilidade e praticidade da embalagem confeccionada.

- O que será que gasta menos papel, uma caixinha ou uma lata? (aluno E. A. T.)

- Será que nós pagamos pela embalagem no preço do produto que compramos? (aluno A. C. D.)

- Por que não fabricam embalagens com alça para o leite? Ficaria mais fácil de colocar no copo. (aluno S. D.)

- Será que eu compraria um produto numa embalagem feia? (aluno A. V.)

Para sanar essas dúvidas, os alunos foram dispostos em círculo e estabeleceu-se uma plenária, com o professor fazendo a intermediação para sanar os questionamentos apresentados. Esse viés da situação-problema inicialmente apresentada visou permitir que os alunos estabelecessem conexões entre a Matemática e outras áreas do conhecimento, com por exemplo Ciências.

\section{Segundo momento}

No início do segundo momento da atividade, propôs-se que os alunos fizessem uma classificação das embalagens construídas por eles no primeiro momento desta atividade, estabelecendo como critério de divisão as que rolam (sólidos que rolam) e as que não rolam (poliedros). Os alunos também deveriam identificar o formato geométrico que as embalagens apresentavam. O objetivo dessa classificação era incorporar as estruturas de conhecimento já estabelecidas pelo aluno nas séries iniciais ao novo conteúdo geométrico a ser apresentado. 
Durante o desenvolvimento da classificação proposta, os alunos fizeram vários comentários dentre os quais se destacaram os seguintes:

- A minha embalagem tem o formato de um quadrado e por isso não rola. (aluno A. P.)

- A minha embalagem é um pacote, e eu não sei se ele rola ou não rola. Dependendo o jeito que eu coloco as coisas dentro ele rola. (aluno T. M. R.)

- A minha embalagem é um retângulo. Não rola. (aluno R. A.)

Por meio da observação e experimentação, os alunos começaram a discernir as características de uma figura geométrica e a usar propriedades para conceituar classes de suas formas geométricas. No nível de visualização, os alunos reconhecem ou reproduzem as figuras geométricas por sua forma, sua aparência global, mas não identificaram explicitamente suas propriedades, fato esse evidente quando o aluno afirma que sua embalagem é um retângulo. Ao ser perguntado por que, responde:

- Porque se parece com um retângulo. (aluno R. A.)

Percebe-se, pela fala do aluno, que ele não sabe discernir uma figura geométrica plana de uma figura geométrica espacial. E essa dificuldade em Geometria talvez seja conseqüência de como esses conceitos foram transmitidos a esses alunos nas séries iniciais.

Embora muitos educadores afirmem que o raciocínio espacial e a Geometria estão relacionados, a prática escolar parece indicar que não se está consciente de quão complexas são as relações que se estabelecem em nossas mentes e nas de nossos alunos, quando se trabalha com figuras espaciais, e se estabelecem relações entre figuras e suas representações. Esse fato faz analisar a importância de se repensar a abordagem de ensino-aprendizagem praticada nas aulas, pois os alunos adquirem a concepção de forma como aquilo que existe à sua volta.

Após várias explicações por parte do professor sobre os conceitos das figuras geométricas planas e espaciais, solicitou-se que os alunos planificassem em uma folha de papel sulfite os seguintes sólidos geométricos: tetraedro, hexaedro, octaedro e cilindro. O objetivo nesse momento era desenvolver a percepção de que para se ter uma figura geométrica espacial é necessário fazer a construção de figuras geométricas planas, da mesma forma como observaram a diferença entre os sólidos que rolam e os que não rolam. Por meio da análise dos conceitos geométricos e de observações e experimentações, os alunos começam a discriminar algumas características das figuras. As propriedades que as figuras geométricas apresentam vão ser utilizadas na criação de classe de figuras. 
Com as planificações construídas, os alunos passaram a elaborar um relatório sobre as diferenças geométricas que aprenderam. Nesse momento, alguns alunos teceram comentários sobre as respostas e também sobre as planificações feitas. Entre eles destacaram-se os seguintes:

- Não consigo deixar meus seis quadradinhos do mesmo tamanho, por isso eles não encaixam para montar certinho o dado. (aluno A. S.)

- O Brasil é penta-campeão no futebol e está rumo ao hexa. Por isso na Geometria o hexaedro são seis quadradinhos montados que formam o que eu chamo de dado. (aluno J. L. S.)

- Nossa! Para montar um cilindro precisei fazer um retângulo e dois círculos. (aluno S. D.)

Com a planificação, percebeu-se que os alunos tinham uma grande dificuldade em usar as unidades de medida, principalmente quando a régua usada estava quebrada e não apresentava o zero. Os alunos identificaram algumas características das figuras geométricas planas, perceberam semelhanças e diferenças entre elas, fatos que se evidenciaram quando comentaram que:

- Um quadrado tem os 4 (quatro) lados com a mesma medida e seus 4 (quatro ângulos medem 90 (noventa) graus. (aluno C. M. S.)

- Um retângulo tem ângulo reto. Mas isso é igual no quadrado. Se eles tem nome diferentes deveriam ter ângulos diferentes. (aluno S. U.)

Percebe-se que, ao desenvolver essas planificações, os alunos encontram-se no nível de análise, pois conseguiram perceber as características das figuras e descrever algumas de suas propriedades, mas não conseguiram relacionar, explicitamente, as diversas figuras ou propriedades entre si. Esse fato ficou mais evidente quando dois alunos afirmaram que o quadrado tem quatro lados iguais e quatro ângulos retos, mas não foram capazes de diferenciá-lo de um retângulo pelas suas propriedades. Os alunos não conseguiam relacionar explicitamente as propriedades geométricas, como por exemplo, não sabiam diferenciar um retângulo por suas propriedades, mas sabiam que um quadrado tem os quatro lados com a mesma medida e os quatro ângulos retos.

Então, as propriedades das figuras passaram a ser ordenadas com lógica e a construção das definições passou a se basear na percepção do necessário e suficiente. Assim, os alunos ficaram sabendo que todo quadrado é um retângulo, mas que nem todo retângulo é um quadrado. Isso só foi possível com a articulação das propriedades dessas figuras. Com o desenrolar das atividades, os alunos passaram a deduzir e compreender o processo dedutivo, mas ainda sem rigor matemático. Nesse momento, os alunos sabiam diferenciar figuras planas de 
figuras não-planas, mas ainda não eram capazes de entender os postulados que rigorosamente apresentam essas diferenças.

Com as planificações construídas, propôs-se aos alunos que fizessem uma sistematização dos sólidos geométricos já planificados (tetraedro, hexaedro, octaedro e cilindro). Essa tarefa exigiu que os alunos usassem os conteúdos anteriormente conhecidos. Com a tarefa resolvida, os alunos sociabilizaram com os demais colegas as respostas encontradas. Nesse momento, alguns alunos teceram comentários sobre as respostas e também sobre a tarefa proposta. Seguem-se alguns deles:

- Um retângulo também pode ser chamado de paralelogramo, pois tem lados paralelos. (aluno I. D.)

- Se um retângulo tem lados iguais dois a dois, o quadrado também tem. (aluno O. M. F.)

- $\quad$ Agora sei que todo quadrado é um retângulo, mas nem todo retângulo é um quadrado. Isso explica a dúvida que eu tinha em relação entre o quadrado e o retângulo terem os 4 (quatro) lados com a mesma medida e terem nomes diferentes. (aluno A. V.)

Essas falas identificam que os alunos, no desenvolvimento dessa tarefa, estão no nível de dedução informal, pois relacionam as figuras geométricas entre si de acordo com suas propriedades, mas não dominam o processo dedutivo. Isso fica evidente quando um aluno expressa ter conhecimento de propriedades geométricas que explicam que todo quadrado é um retângulo e, que todo retângulo é um paralelogramo, ou seja, os alunos conseguem articular as propriedades das figuras geométricas, mas apresentam dificuldades em se servir dessas propriedades para obter novos resultados.

O professor, então, iniciou uma generalização das figuras geométricas, de modo a classificar os poliedros e os sólidos, inserindo a nomenclatura da área e os conceitos de aresta, face e vértice. Nesse momento, inicia-se o rigor matemático, é o momento de o aluno sair do conhecimento informal e passar para o conhecimento formal. Dessa forma, os alunos conseguem estabelecer inter-relações entre propriedades de figuras e entre figuras e são capazes de deduzir propriedades de uma figura e reconhecer classes de figuras. As propriedades das figuras são ordenadas logicamente e a construção das definições se baseia na percepção do necessário e do suficiente. As demonstrações podem ser acompanhadas, memorizadas, mas ainda são dificilmente elaboradas.

A dedução é entendida como um caminho para estabelecer uma teoria no interior de um sistema axiomático, em que são compreendidos os termos não definidos, os axiomas, os postulados, as definições, os teoremas e as demonstrações. 
Assim, para adentrar em um novo nível, o professor solicitou que seus alunos identificassem quantos triângulos, retângulos e quadrados foram utilizados para a planificação dos poliedros (tetraedro, hexaedro e octaedro). Para resolver essa tarefa, os alunos precisaram rever as planificações anteriormente construídas. Dessa forma, fez-se a interação do conteúdo apresentado numa edificação mental e ordenada.

Com o desenrolar das atividades, notou-se que os alunos passaram a perceber as características das figuras planas e dos poliedros - tetraedro, hexaedro e octaedro - e passaram a descrever algumas de suas propriedades, deduzindo-as informalmente. Dessa forma, os alunos passaram a relacionar as figuras entre si de acordo com suas propriedades. Isso se observa pelos seguintes relatos:

- Para planificar meu octaedro, eu usei 8 (oito) quadrados. Então, também posso dizer que usei 8 (oito) retângulos com os lados iguais entre si. (aluno J. M. S.)

- Se eu grudar dois triângulos eu tenho um quadrado. Então se o quadrado tem 4 ângulos de 90 graus, a soma desses ângulos dá 360 graus. Logo, cada triângulo vai ter a soma de seus ângulos igual a 180 graus. (aluno P. L.)

Os alunos passarão a compreender o processo dedutivo, a recíproca de um teorema, as condições necessárias e suficientes, mas ainda se observa a necessidade da utilização de um rigor matemático. Para introduzir essa necessidade, propôs-se a tarefa de calcular algebricamente as áreas das figuras planas envolvidas na planificação dos sólidos (tetraedro, hexaedro e octaedro). Para a realização dessa tarefa, o professor inicialmente explanou a relação área/superfície nos polígonos utilizados para a confecção dos poliedros. Então os alunos partiram para os cálculos e para os comentários:

- Se para calcular a área de um quadrado eu tenho que multiplicar a medida da base pela medida da altura, para achar a quantidade de papel usada para fazer um hexaedro basta pegar esse resultado e multiplicar por 6 (seis). (aluno E. R. K.)

- Se a área de um quadrado é a multiplicação da medida de sua base pela medida de sua altura, a área do retângulo segue a mesma idéia: medida da base vezes a medida da altura. (aluno I. G. L.)

De posse dos sólidos planificados, a realização dos cálculos tornou-se mais fácil. Para a resolução dos cálculos foi necessário fazer uso dos conhecimentos adquiridos ao longo da atividade. Este ciclo de tarefas desenvolveu-se no sentido de levar os alunos a compreenderem os enunciados, as terminologias e as técnicas convencionais, sem, no entanto, 
deixar de valorizar e estimular suas hipóteses e estratégias pessoais. Desse modo, os alunos atingiram um nível de abstração capaz de estabelecer a diferença entre os objetos e a sua essência.

\section{Algumas Considerações}

A Geometria pode ser vista como parte de uma ciência dinâmica, flexível e maleável às inter-relações entre os seus vários conceitos e os seus vários modos de representação. O conhecimento de Geometria ajudou, ajuda e ajudará o aluno a apreciar e valorizar as formas que existem ao seu redor, proporcionando um relacionamento entre as idéias geométricas com os números e as medições.

Nesse entender, a tendência de ensino-aprendizagem de Matemática, através da Resolução de Problemas como ponto de partida à construção de conceitos matemáticos, sugere que o problema matemático instigue o aluno e o leve à aprendizagem. Ela pretende que o aluno deixe sua tradicional postura passiva em sala de aula e passe a ter uma postura ativa.

O modelo da van Hiele contribui com essa tendência de ensino, pois por meio desse modelo verifica-se que o modelo de raciocínio em Geometria estabelece que os alunos, quando sujeitos a um processo de aprendizagem adequado, desenvolvem o seu pensamento geométrico passando por cinco níveis, de forma que cada aluno só atinge um determinado nível após ter passado pelo anterior. Assim, em conhecimentos geométricos a possibilidade de visualizar as figuras planas e espaciais em diferentes posições contribui para o entendimento de suas características.

O desenvolvimento de toda a atividade serviu para orientar, comunicar, fazer medidas e apreciar formas. Enfatizou-se a importância ao destacar que os conceitos geométricos levam os alunos a desenvolver um tipo especial de pensamento que lhes permite compreender, descrever e representar, de forma organizada, o mundo em que vivem.

Analisando os resultados obtidos pela fala dos alunos quanto à aprendizagem de conceitos segundo os níveis de van Hiele, nota-se que os alunos encontravam-se no primeiro nível. Da prática docente, observou-se que, a princípio, o aluno não apresenta grandes dificuldades para entender as propriedades essenciais das figuras geométricas planas que fazem parte de seu dia-a-dia, principalmente as relações percebidas visualmente. 
As atividades realizadas foram extremamente ricas, pois permitiram uma reflexão sobre a vivência do aluno e enfocaram os conceitos geométricos envolvidos na construção da embalagem, assim como as habilidades visuais, táteis, cognitivas e motoras que a atividade mobilizou. Ao final da atividade, foi possível observar que os alunos passaram a conhecer as fórmulas para a realização dos cálculos, mas se confundiam quando, em um mesmo exercício, precisavam utilizá-las para a realização da atividade proposta. Logo após a solução da situação-problema proposta, os conceitos matemáticos foram sistematizados pelo professor, utilizando-se do rigor e do formalismo característicos da Matemática.

Nesse entender, o que caracteriza o ensino de Geometria, na maioria das vezes, é a predominância da concretização sobre a simbolização. Mais importante que definir as ações meramente repetidoras é observar, descrever, comparar, tocar e construir. Para isso, é necessária, em sala de aula, uma Geometria combinada com conhecimento das atividades que as pessoas desenvolvem no seu cotidiano, a fim de, a partir delas, desenvolver todo o processo de ensino. O aluno também passará a ter um maior interesse e uma maior curiosidade pela Matemática, neste caso pela Geometria.

Dessa forma, as atividades desenvolvidas, baseadas na resolução de problemas, procuraram proporcionar uma aprendizagem contextualizada. Ressalta-se que, até o presente momento, a empresa ainda não respondeu ao e-mail da turma se posicionando quanto à possibilidade de aceitar a sugestão dada pelos alunos em relação à confecção de uma embalagem de $200 \mathrm{ml}$ para o armazenamento de leite.

Espera-se, com essa proposta de atividade, venha contribuir para a compreensão de outras situações desafiadoras que se apresentarão aos alunos por meio de atividades desenvolvidas pelos professores de outras áreas do saber.

Enfim, este artigo traz algumas considerações importantes e fornece informações para os professores que estão dando passos no caminhar em busca de soluções para o problema de ensino-aprendizagem em Geometria.

\section{Referências}

ALLEVATO, N. S. G. Associando o Computador à Resolução de Problemas Fechados: Análise de uma Experiência. 2005. Tese (Doutorado em Educação Matemática) - Instituto de Geociências e Ciências Exatas, Universidade Estadual Paulista Julio de Mesquita Filho, Rio Claro, 2005.

BRASIL. Ministério da Educação. Parâmetros Curriculares Nacionais: Matemática. Brasília: MEC/SEF, 1998. 
CROWLEY, M. L. The van Hiele model of the development of teometric Thought. In M. M. Lindquist (Org.), Learning and teaching geometry, k-12 (pp. 1-16). Reston, VA: NCTM, 1987. EVES, H. Introdução à história da Matemática. 2a edição. São Paulo: Editora UNICAMP, 1997.

HOGBEN, L. Maravilhas da Matemática. 2a edição. 3a impressão. Porto Alegre: Editora Globo, 1970.

LINDQUIST, M. L.; SHULTE, A. (orgs.). Aprendendo e ensinando geometria. São Paulo: Atual, 1994. LOPES, S. R. Metodologia do ensino da matemática. Curitiba: Ibpex, 2005.

LORENZATO, S. Por que não ensinar Geometria? In: Educação Matemática em Revista - SBEM 4, 1995, p. 3-13

MACHADO, N. J. Matemática e Realidade: análise dos pressupostos filosóficos que fundamentam o ensino da matemática. São Paulo: Cortez, 1987.

MORELATTI, M. R. M.; SOUZA, L. H. G. de. Aprendizagem de conceitos geométricos pelo futuro professor das séries iniciais do Ensino Fundamental e as novas tecnologias. Educ. rev. [online]. 2006, n. 28, pp. 263-275. ISSN 0104-4060. doi: 10.1590/S0104-40602006000200017. NASSER, L.; SAN'ANNA, N. F. P. Geometria segundo a teoria de van Hiele. Projeto Fundão. 4ạ edição, 2004.

ONUCHIC, L. R. Ensino Aprendizagem de Matemática através da Resolução de Problemas. São Paulo: Editora Unesp, 1999.

ONUCHIC, L. R. Novas Reflexões sobre o ensino-aprendizagem de matemática através da resolução de Problemas. In: BICUDO, M. A e BORBA, M. (orgs) Educação Matemática - pesquisa em movimento, São Paulo, Editora Cortez, 2003.

Ostrower, F. Criatividade e Processos de Criação. São Paulo: Vozes, 1983.

Pereira, G. A.; Silva, S. P.; Motta Jr, W. S. O Modelo van Hiele de Ensino de Geometria aplicado `a 5a e 6a séries do Ensino Fundamental Faculdade de Matemática. - Uberlândia: Universidade Federal de Uberlândia, 2005. FAMAT em Revista - Número 05 - Setembro de 2005

POLYA, G. A arte de resolver problemas: um enfoque do método matemático. Tradução e adaptação: Heitor Lisboa de Araújo. Rio de Janeiro: Interciência, 1949.

SCHROEDER, T.L., LESTER Jr., F.K. Developing Understanding in Mathematics via Problem Solving, TRAFTON, P.R., SHULTE, A.P. (Ed.) New Directions for Elementary School Mathematics. National Council of Teachers of Mathematics, 1989. 
SOUZA, M. J. A. Informática Educativa na Educação Matemática: estudo de geometria no ambiente do software Cabri - géomètre. Fortaleza, CE: Universidade Federal do Ceará, 2001. Dissertação de Mestrado.

VAN DE WALLE, J. A. Elementary and Middle School Mathematics. New York: Logman, 2001. VAN HIELE, P. M. Structure and insight: A theory of mathematics education. Orlando, FL: Academic Press, 1959.

Ana Cristina Schirlo: Mestranda em Ensino de Ciência e Tecnologia - UTFPR/PG, docente da Secretaria de Educação do Estado do Paraná, Ponta Grossa, Paraná. acschirlo@gmail.com

Sani de Carvalho Rutz da Silva: Doutora em Ciências dos Materiais - UFRGS e Professora do Programa de Pós-Graduação em Ensino de Ciência e Tecnologia Universidade Tecnológica Federal do Paraná (UTFPR/PG), Ponta Grossa, Paraná. sani@utfpr.edu.br 